\title{
Constructing Knowledge and Ignorance in the Social Information Worlds of Young Mothers
}

\author{
Devon Greyson \\ BC Children's Hospital \\ Research Institute, \\ University of British Columbia \\ Vancouver, Canada \\ dgreyson@bcchr.ubc.ca
}

\author{
Heather O'Brien \\ School of Library, Archival \& \\ Information Studies \\ University of British Columbia \\ Vancouver, Canada \\ h.obrien@ubc.ca
}

\author{
Jean Shoveller \\ School of Population \& \\ Public Health \\ University of British Columbia \\ Vancouver, Canada \\ jean.shoveller@ubc.ca
}

\begin{abstract}
The socially-constructed information worlds within which individuals live, work, and play necessarily shape their information practices. One way in which this occurs is through the social construction of knowledge, expertise, and ignorance, including which actors are considered to possess authoritative knowledge through administrative authority or "lay" expertise. Using Adele Clarke's situational mapping techniques, this paper examines the discursive construction of knowledge and ignorance in the information worlds of young mothers in the Greater Vancouver region of Canada. Data was collected via observations at school-based Young Parent Programs and interviews with 37 young mothers over a 15-month time period. Gendered and racialized young parent social worlds discursively constructed the "teen mom" as knowledgeable in matters of sexuality and technology, and ignorant in matters of parenting and health. Further, certain forms of experiential expertise common to marginalized groups were sometimes constructed in such information worlds as forms of ignorance. Recognizing the diversity of knowledge and expertise among young mothers rather than perceiving them as unilaterally information poor may lead to improved information and support services for young parents.
\end{abstract}

\section{Keywords}

Information worlds, knowledge, expertise, situational analysis, youth

\section{INTRODUCTION}

The socially-constructed information worlds within which individuals live, work, and play necessarily shape their information practices. One way in which this occurs is through the social construction of knowledge, expertise, and ignorance, including who is considered to possess authoritative (true or reliable) knowledge, either through administrative authority (e.g., "expert" status such as that conferred by professional credentials) or "lay" expertise (e.g., experientially-acquired skill). The lived experiences of individuals whose expertise is regularly contested due to

ASIST 2017, Washington, DC | Oct. 27-Nov 1, 2017

Authors Retain Copyright. their social locations (e.g., ethnicity, age, socioeconomic class markers) are necessarily affected by others' assumptions regarding their knowledge and/or ignorance. This research focuses on one such group: young mothers.

Young mothers in contemporary North America live within a broader social and political climate that casts parents in their teen years and early twenties as knowledge deficient, as well as socially and medically problematic. In efforts to improve outcomes for young mothers and their children, multiple stakeholders provide information to, and collect information from, young mothers. This occurs both formally (e.g., by public health or social welfare) and informally (e.g., by peers and neighbors) in physical and virtual spaces. Such information interventions, as well as young mothers' own information behaviors and practices (analyzed in Greyson, 2016, 2017; see also related work on first-time mothers by Loudon, Buchanan, \& Ruthvan, 2016) are situated in socially-constructed worlds. Within these worlds, information, knowledge, and expertise are negotiated in order to determine who needs information, who is knowledgeable, and whose knowledge is valued as expertise. This analysis explores the social constructions of knowledge and ignorance in the information worlds of a group of young mothers in the Greater Vancouver region of Canada.

\section{INFORMATION WORLDS}

"Information worlds" is a phrase commonly used for conceptual spaces in which information-related activities, behaviours, and practices take place, yet there remains some lack of clarity around what is intended by this metaphor (Yu, 2012). Burnett and Jaeger's (2008; Jaeger \& Burnett, 2010) information worlds theory integrates Chatman's (1991) small worlds of marginalized people in localized contexts with Habermas' (1991) conceptualization of the public sphere, resulting in a multi-level theory that asserts that information worlds overlap and interact at levels from the individual (micro) through community (meso) to whole societies (macro). Jaeger \& Burnett (2010) focus on five aspects of information worlds: social norms, social types, information value, information behaviour, and boundaries at which information worlds come into contact with each other. 
According to sociologist Adele Clarke (2005), "Social worlds...generate shared perspectives that then form the basis for collective action..., while individual and collective identities are constituted through commitments to and participation in social worlds and arenas" (p.45). Taking a postmodern, Foucauldian approach, Clarke conceives social worlds as containing structures and actors of various social types. These social worlds engage in struggle with each other over boundaries, social norms, and discourses within arenas in a manner similar to that of Burnett and Jaeger's (2010) information worlds. Social norms, actors of various types, constructed values, and negotiations of relationships and boundaries are common elements of both situational analysis and information worlds theory, which may be integrated to focus specifically on the analysis of social information worlds. By using Clarke's situational analysis methods to investigate social information worlds of young parents - a population whose knowledge and expertise is contested-we may elucidate values and norms of and about actors within these worlds, providing insight into the construction of their information behaviours and practices.

\section{CONSTRUCTIONS OF KNOWLEDGE, IGNORANCE, AND EXPERTISE IN SOCIAL INFORMATION WORLDS}

The study of social constructions of knowledge, or the ways people construct, act on, and institutionalize shared understandings (Berger \& Luckmann, 1967), has been a mainstay of sociological inquiry since the mid $20^{\text {th }}$ century. After the postmodern turn, in which many social theorists rejected the notion of universal metanarratives, inquiry into social knowledges became an explicitly multi- and interdisciplinary endeavor, incorporating science and technology studies as well as more traditional sociological and philosophical traditions, and using discourse analysis as a core method for interrogating knowledge constructions and related social practices (see, for example, Camic, Gross, \& Lamont, 2011). Tuominen and Savolainen (1997) laid the groundwork for discursive inquiry into the social construction of information use, which has been influential to scholars of information behavior and practices (see for example Karlova \& Fisher, 2013; McKenzie, 2003).

While a great deal of study has gone into understanding knowledge production, the phenomenon of ignorance and the structures that shape it are a newer area of investigation. Proctor (2008) identifies three types of ignorance, which have been further theorized by intersectional scholars who identify the interconnections between race and epistemologies of ignorance. These are: 1) ignorance as naïve state that may be remedied by acquiring knowledge (e.g., white privileged ignorance of racism (Sullivan \& Tuana, 2007)); 2) ignorance as lost realm of knowledge forgone (as when English colonists suppressed knowledge of the abortifacient properties of native flora when importing plants to Europe (Schiebinger, 2004)); and 3) ignorance as strategic ploy to maintain doubt (evident in situations such as black slaves in the Americas feigning ignorance for their own safety). Young people are frequently perceived to inhabit a naïve state, requiring knowledge acquisition (often via formal education) in order to properly mature. However other forms of ignorance may also be re/produced in certain youth contexts. For example, young people may actively construct ignorance in order to perpetuate uncertainty (e.g., to evade responsibility or surveillance), or may possess knowledge that is suppressed or devalued by adults who encourage pursuit of other types of knowledge. Similar to intersectional agnatology, Chatman's information worlds theories for marginalized populations recognize strategic ignorance practices such as secrecy, apathy, and disinformation, considering them hallmarks of "information poverty" (Chatman, 1996) and a highly surveillanced "life in the round" (Chatman, 1999).

Actors in social information worlds engage in tensions and negotiations in order to determine who lacks knowledge, who has knowledge, and whose knowledge counts as expertise. Within these social worlds, there are individuals and 'types' of people who are looked to as authoritative information providers. These people may possess a high level of knowledge-related cultural capital (assets that facilitate social mobility, e.g., education, professional credentials), or they may rely on "lay" or experiential expertise. Building on Collins and Evans (2007; 2002) taxonomy of "expertises" and Eyal's (2013; Eyal \& Buchholz, 2010) distinction between "experts" and "expertise," we may conceptualize knowledge and expertise as belonging both to laypeople with experiential expertise and to formal experts in a field when exploring discourses of knowledge in young parent social worlds. Many information worlds include both "official" or "authoritative" information sources and informal or social information sources, but individuals attribute value and trust to sources in varying ways. Studies of information behaviour have found resonance in theories that acknowledge the general human inclination toward easy access and "good enough" information, such as the principle of least effort (Zipf, 1949) and sense-making (Dervin, 1992; Savolainen, 1993). In practice, these theories suggest that, while "expert" information may be desired, trusted, and even actively sought on certain topics and by certain information users, sources that pose the least barriers and are the most congruent with the seeker's life are typically consulted first - be this a quick Internet search or asking friends or coworkers for their input. Social groups may have informal "information specialists" who are the group "knowers" with expertise on particular topics. Social media fora or face-to-face gathering spaces may serve as "information grounds" (Fisher \& Naumer, 2006) for peerto-peer information exchange.

\section{THE CONTEXT FOR YOUNG MOTHERHOOD}

Young pregnancy and parenting have long been constructed as a societal problem in North America (Bonell, 2004; Furstenberg, 1976; Kelly, 2000). Despite a decline in teen pregnancy and childbearing over the past half century (Duncan, 2007; Langille, 2007), an infantilizing discourse 
persists over the alleged crisis of "children having children" (Fields, 2005). Public health constructs teenage pregnancy as a socially contagious "disease" (Barcelos, 2013; Breheny \& Stephens, 2010) that requires preventative and remedial education and surveillance. While sociomedical research historically found an association between young childbearing and poorer outcomes, both social (Basch, 2011; Hanna, 2001; Hoffman \& Maynard, 2008), and medical (Dryburgh, 2000; Fraser, Brockert, \& Ward, 1995; Scholl et al., 1992), recent evidence indicates that such differences are in fact attributable to underlying social determinants rather than maternal age itself (Gold, Kawachi, Kennedy, Lynch, \& Connell, 2001; PenmanAguilar, Carter, Snead, \& Kourtis, 2013). Indeed, for some young mothers, becoming a parent is associated with significant improvements to their health, education, and social welfare status, providing a valued social role, inspiring career aspirations, and bringing community support (Anwar \& Stanistreet, 2015; Seamark \& Lings, 2004). Despite growing evidence of the complexity of the effects of early parenthood on the lives of young mothers and their children, public health, social science, and medicine interact with media narratives and dominant cultural values to co-construct and reinforce the notion of the "teen mom" (a label commonly applied to youngappearing mothers in their teens and early 20's) as morally problematic (Chabot, Shoveller, Johnson, \& Prkachin, 2010). In her ignorance, she is either a passive victim or a poor decision-maker (Kelly, 2007), reinforced by racialized and classed social narratives (Barcelos \& Gubrium, 2014).

By portraying young mothers as immature and inexperienced, society at large discursively constructs the "teen mom" as ignorant. Young mothers, as well as those tasked with educating them in attempts to remedy their perceived ignorance (lack of knowledge), are situated within and amidst socially-constructed worlds. This analysis centers on the social worlds that host and implement formal and informal information interventions aimed at improving the well-being of young mothers and their children by means of education and/or surveillance. The objective herein is to explicate social worlds within which young mothers seek, use, and share information, describe the roles and tensions among the various social worlds at play, and characterize discourses of knowledge and ignorance regarding young mothers, including their intersections with young mothers' social locations.

\section{METHOD}

\section{Study Setting}

This study took place in the third largest metropolitan area in Canada, Greater Vancouver, home to 2.3 million people (Statistics Canada, 2012). Each city within the region hosts a Young Parent Program (YPP), which serves as a hub for secondary education, health, childcare, and social support programming to young parents. External to the YPPs are a variety of health and social support services, which often work in collaboration with the YPPs to provide services ranging from food assistance to health education to young parents and their children. The primary locations for this study's fieldwork were two Greater Vancouver YPPs. Additional data collection was conducted at community organizations that serve young parents, including the nonschool based setting for a third YPP.

\section{Data Collection}

Data was collected via ethnographic observation at YPPs and individual interviews with young mothers. Data collection began in October 2013 and continued through December 2014. Interview participants were initially purposively recruited from YPPs to select pregnant or parenting youth. As the study progressed, interview participants were purposively and theoretically sampled from YPPs as well as from other community organizations that provided young parent services, to provide additional diversity of age and education, to engage youth not in school, and to test emerging theories. Semi-structured interviews covered a range of topics spanning health, housing, childcare and parenting, education and career, and information practices. Interviewees were invited to participate in follow-up interviews approximately every four to six months (for a maximum of three interviews within the study timeframe) in order to follow participants' evolving lives and practices.

\section{Data Analysis}

This article presents a situational analysis (Clarke, 2003; 2005) of the social information worlds of young mothers. Situational analysis is a grounded theory-based analytic method that uses visual diagramming methods to analyze social worlds and elucidate the tensions therein, the power relationships among actors, and the discourses they construct. In situational analysis, social worlds are "universes of discourse," through which individuals and social groups co-construct each other (Clarke, 2005, p. 55). Situational analysis has only rarely been used within information science research, and typically been applied to conceptualizing library spaces, programming, and roles (Batool \& Webber, 2016; Grace \& Sen, 2013) rather than exploring users' information worlds. For the current analysis, member-checked interview transcripts and observational field notes were first coded and analyzed in accordance with constructivist grounded theory (Charmaz, 2007, 2009), using QSR NVivo 10 software. We then engaged the coded data in a variety of Clarke's situational analytic data mapping exercises in order to interrogate the social information worlds of young mothers. Specifically, we used: a) situational mapping to classify and examine relationships among human and non-human actors in the social worlds, b) social worlds/arenas mapping to focus in on the worlds within the young parent arena, and c) positional maps to flesh out discourses of ignorance and knowledge regarding study participants. For more detail on these mapping methods, refer to Clarke $(2003,2005)$. 


\section{RESULTS}

Over the course of 15 months of data collection, we conducted 50 days of naturalistic observation at YPPs and interviewed 37 young mothers ages 16-22. All interview participants participated in 90-minute individual intake interviews. Eighteen young mothers completed a second interview of approximately 45-60 minutes four to six months after their intake interview, and three also completed third interviews, which were also 45-60 minutes in length. Over half of the young mothers in this study were visible minorities, $40 \%$ of them had at least one parent born outside of Canada, and six of the 37 were themselves immigrants. Three identified at one or more interview as bisexual or pansexual and two as questioning or unsure; the remainder identified as straight or heterosexual. One mother identified as gender non-binary, and the rest as women.

In analyzing the socially-constructed information worlds that made up the young parent arena, three key findings emerged. The first was that while experts from various social worlds aimed to educate young mothers, young mothers also possessed and developed lay expertise. The second was that young mothers were discursively constructed as paradoxically ignorant and knowledgeable. The third was that the relationships among social worlds, as well as the discourses of knowledge and ignorance, were constructed in a gendered and racialized manner.

\section{Information Worlds in the Young Parent Arena}

Through situational mapping of coded interview transcripts and observation field notes, a young parent social arena emerged that was centered on the YPPs and contained multiple, overlapping, health-related social information worlds. Chief among these were the worlds of the organizations that participate in the day-to-day administration of the YPPs: the secondary school and the associated child daycare facility. These two social worlds were ones with which student parents in the YPPs interacted every school day. In addition, professionals from public health, nursing, and non-governmental organizations (both faith-based and secular) were regularly on site, providing programming and recruiting participants for their own services. Figure 1 contains a social information world map of this young parent arena, centering on the YPPs. Larger ellipses represent worlds that were more prominent in the data and, while it is impossible to depict all interrelationships among worlds in a two-dimensional image, overlap indicates porous boundaries among related social worlds.

For many young mothers, support from their family of origin was instrumental to their ability to attend school while parenting, and family members were key sources of information and support. Some young mothers who did not live with their families received government support, allowing them to live in foster care while parenting or to live independently under legal agreements with the province called Youth Agreements. Family and "the State"

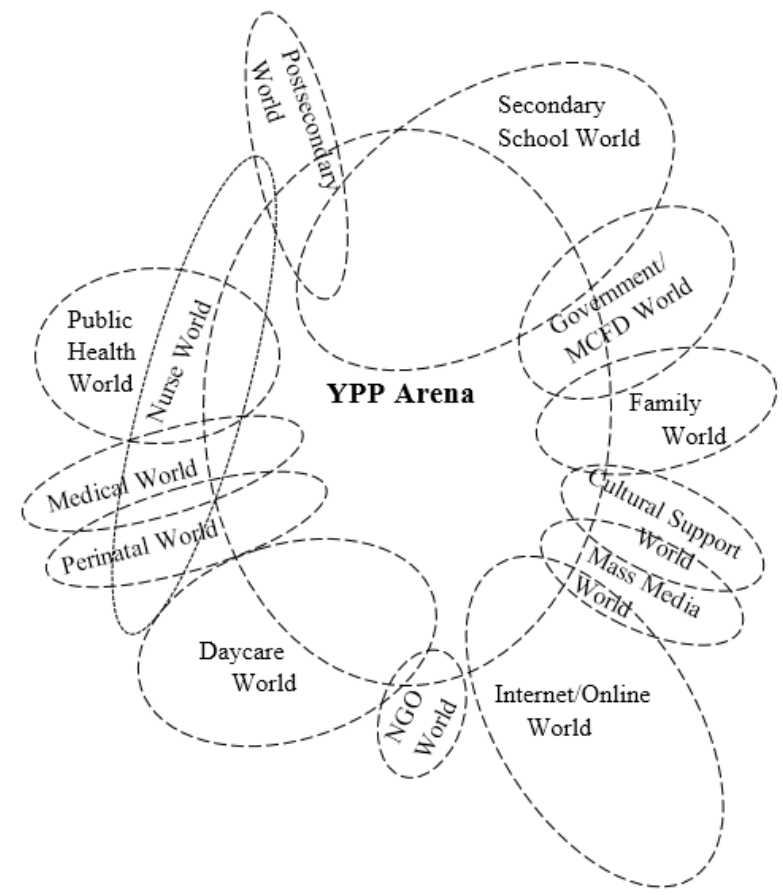

Figure 1. Social Information World Map: Young Parent
Arena.

were two social worlds that were ever-present even without representatives of those worlds physically setting foot in the YPP. This presence took the form of family and government support for young parent success, as well as family conflict issues, the workings of government surveillance, and the related threat of child apprehension. Cultural groups, ranging from religious congregations to refugee settlement services, reflected aspects of students' social arenas, and provided social worlds external to the YPPs that played an important role in the experiences and identities of some young mothers. Medical communities of various types were prominent within the young parent arena, for example the overlapping worlds of western medicine, nurses, public health, and the perinatal health community. The influence of each of these authoritative health information worlds was strong, as the health information they provided was frequently referred to as expert information. There was wide variation in the degree of direct contact between these worlds and the YPP programs, with medicine being the most separate and public health nursing the most intertwined.

The Internet was a major social world interacting with the young parent arena, working its way into every significant information issue eventually, whether via smartphone use in the classroom, as a link for relationship maintenance with peers, as a reference source more frequently consulted than any print material, or as a topic for regular discussion and concern (e.g., online privacy risks and norms). The Internet as used by young mothers in this study was an important 'virtual' social world, which interacted with the mass 
media-most particularly the genre of "reality" television shows such as MTV's 16 and Pregnant and Teen Mom.

These multiple social information worlds interacted with each other, sometimes directly (as in the case when a student mother's own parents came to register her for the YPP alternative school) and sometimes indirectly (as when youth workers would help young mothers navigate paperwork to apply for government benefits). While they sometimes worked in concert to reinforce each other's information, they also engaged in conflicts over which health information was current and authoritative, as well as the extent to which young mothers were in need of education and surveillance.

\section{Constructions of Expertise in Young Mother Information Worlds}

The social information worlds in this study contained actors representing many positionalities within the young parent arena. Some actors, such as teachers, doctors, parents, and public health nurses, were officially tasked with educating young mothers on health-related matters, while others were more arms-length to these information interactions. The degree to which these actors were constructed as experts and non-experts also varied, as vertical (within a social world) and horizontal (across social worlds) hierarchies and power dynamics shaped administrative authority. Expert status was conferred via formal credentialing or by approval of someone with administrative authority. However, expertise could be constructed in multiple, sometimes shifting ways. A person could recognize herself as holding expertise based on extensive experience, while others could construct a position of expertise for someone by deferring to or consulting her in matters on which she was experienced.

Major actors in the core YPP social worlds of secondary education and daycare included teachers, youth workers, and daycare staff, all of whom were positioned as credentialed experts (in academics, supportive services, and parenting skills) in relation to student-parents. Additionally, the YPPs were sites of frequent visits by outside health educators such as public health nurses, student nurses from local colleges, and young parent support workers of various types from local non-governmental organizations, all of whom contributed their expertise to the program by providing various forms of health education. Although not recognized as part of a formal community of experts, young parents acted as information sharers and mediators within the young parent arena in a variety of ways, some of which conferred a form of lay expertise status among peers.

Other young people within a variety of social information worlds - including schools, cultural support groups, and the family domain - often viewed young parents as lay experts in matters of reproductive labor, inclusive of childbearing and parenting, but extending to intimate relationships and household management as well. In interviews, young mothers described other youth in their communities approaching them with questions about pregnancy and parenting, often when suspecting or learning that they might themselves be pregnant. Seventeen year old young mother Crystal ${ }^{1}$ explained, "I've had lots of friends who have had questions about, 'Oh, I think I might be pregnant,' or 'I'm pregnant right now... what should I do? Should I abort? Should I keep it? How was it for you?"' Young mothers also spoke of friends seeking their advice on family issues beyond pregnancy and infant caregiving. Eighteen-year old Rey described her friends as being very active in information sharing according to their various areas of lay expertise. In addition to checking with each other about health and relationship concerns, she explained that sometimes, "They come with a question like 'What do I do when I don't know how to take care of my daughter' or, you know, financially and stuff like that."

In addition to acting as a peer resource for expertise on matters of reproductive labor, some young mothers were recognized for expertise with childcare and parenting by older community members. This type of situation arose in this study most frequently in Indigenous families whose intergenerational parenting practices had been disrupted by structures of colonization, such as residential schools and child welfare apprehension. JBiebs, a 16-year old expectant mother, had been participating in the care of her younger brother since his infancy. Although JBiebs was pregnant with her first child at the time of our first interview, she was already recognized in her family and community as a reliable parenting expert. When asked if there were people who came to her for information or advice about child caregiving, JBiebs explained,

Surprisingly, my mom does. 'Cause I've been raising my brother and my brother loves my mom, he loves her so much, but he acts different around her 'cause he thinks he can get what he wants and stuff[....]I tell my mom..."I don't raise [him] that way."...[S] he has asked me a few times, like, "Oh, [he] is asking for this" or "[He] wants this, should I give it to him?" I'm, like, "Does he deserve it?" Like, I'll bring her through those and she can make the decision herself. [...Also] my friend's mom. I used to babysit her son and her niece at the same time so she always asked me, like, "Oh what do I do, my baby is teething?" And I'm, like, okay, well I just told her, "Give him frozen waffles [to suck on in order to soothe his gums. I know] it helps 'cause that's what I did with my little brother."

There were also certain topics on which YPP students demonstrated a higher level of proficiency and knowledge than adults formally positioned to educate them. This happened in a variety of knowledge areas ranging from parenting to technology, and most prominently in the area

1 All names used to refer to study participants are pseudonyms. 
of information and communications technology. During observations, there were myriad small instances of teachers or youth support workers asking students to either search online for an answer to a class question or to explain a new media app or platform to the adults in the room. For example, teacher Roger asked for student help finding online video tutorials the class could watch, and visitors from a community-based young parent support program asked young parents to explain new smartphone apps. While this type of expertise was frequently devalued in young parent social worlds as a natural attribute of contemporary youth who are "digital natives" (Palfrey, 2008; Prensky, 2001), youth were at times positioned as valued guides and instructors whose knowledge was actively sought by adults.

At times, young parents were constructed as local experts within social worlds due to acknowledged work and experience on their own behalf. Twenty-year old Riley, for example, completed secondary school as a young mother via a YPP. After beginning college with a career goal of social work or nursing, Riley noted that she had become a resource for the very workers whose job it had been to support her and other young parents. By drawing on the combination of her experience as a young parent and the new medical information she was learning in college, she noted that, 'I'm able to help them out 'cause they're not-a lot of them aren't... health people. They're just for support. So sometimes I'm able to help with them or share with them." Although aware that she had developed scientific knowledge that was out of the support workers' scope, Riley still moderated her explanation of this information mediation, correcting her initial wording to imply that she was "sharing" information with support workers previously positioned as experts to support her, rather than providing help in their area of weakness.

Actors in the various young parent health information worlds were engaged in constant negotiations over the boundaries of knowledge and expertise, such as when teacher Roger asked the young mothers to help him use YouTube or aspiring nurse Riley provided health information to her former support workers. Resulting from these negotiations, in the context of broader societal constructions of young mothers, were discourses that represented and maintained power relations. The following section presents a positional mapping-based exploration of these discourses.

\section{Discourses of Knowledge and Ignorance Applied to Young Mothers}

Actors within multiple social worlds provided health information to young mothers based on the construction of young mothers as information deficient, and a reliance on health behavior models that suggest that receipt of information leads to knowledge and ultimately behavior change to improve health outcomes. However, within the young parent arena and related social worlds, young mothers were discursively constructed as both knowledgeable and ignorant. These discourses were not uniform but rather varied and intermingled across and within given subject areas. Table 1 summarizes a positional map of the basic discursive constructions of knowledge and ignorance by subject areas ranging from the social to the technical.

\begin{tabular}{llll}
\hline & $\begin{array}{l}\text { Social/ } \\
\text { sexual }\end{array}$ & $\begin{array}{l}\text { Practical/ } \\
\text { parenting }\end{array}$ & $\begin{array}{l}\text { Technological/ } \\
\text { information }\end{array}$ \\
\hline $\begin{array}{l}\text { Knowledgeable/ } \\
\text { Experienced }\end{array}$ & $\begin{array}{l}\text { Promiscuous } \\
\text { "babymamas" }\end{array}$ & $\begin{array}{l}\text { Experienced } \\
\text { caregivers }\end{array}$ & Digital natives \\
Ignorant/Naïve & $\begin{array}{l}\text { Victims of } \\
\text { predators }\end{array}$ & Risky parents & $\begin{array}{l}\text { Technology } \\
\text { poor }\end{array}$ \\
\hline
\end{tabular}

Table 1. Discourses of Young Mother Knowledge and Ignorance.

\section{Social and Sexual Knowledge}

Young mothers are subject to a great degree of social stigma, spanning health care (SmithBattle, 2013), education (Kelly, 1997), and public discourse (Kelly, 1996; Yardley, 2008). Nearly every mother in this study described having been stereotyped as "slutty" by the media, other young people, and older people in their communities. Most expressed frustration at the unfairness of this assumption that teenage mothers are promiscuous. As 16-year old Alex pointed out, "Some people have sex once and get pregnant. But it's still perceived as you've slept with this [large] amount of people." The "teen mom" was constructed by actors in most of the young parents' social worlds as sexually experienced, particularly as compared with nonparenting peers. In some cases these young women were cast as calculating and manipulative (e.g., getting pregnant to "trap" a man), while others were portrayed as naïve girls who had been taken advantage of by older men, removing attribution of agency along with blame. The dominant paradox of sexual experience (scheming promiscuity) yet ignorance (presumed non-use or ineffective use of contraceptives) failed to capture the reality of many young mothers in this study.

\section{Practical Parenting Knowledge}

In contrast with discourses related to sexual knowledge, the dominant construction of young mothers regarding parenting was that of ignorance. Informally, in families and community spaces, it was common for young mothers to receive unsolicited child caregiving advice from wellintentioned laypeople, or what one participant called "community grandmas." The YPP spaces were explicitly created with the mandate to educate young parents, via both secondary school curricula and parenting-specific interventions and support. In addition to providing academic instruction, YPPs were host to visiting experts who provided parenting instruction, such as formula bottle preparation and child sleep training, in accordance with current public health guidelines. Both lay advice and formal instruction were provided to remedy the perceived information needs of young parents. 
In interviews, however, it became clear that it was common for young mothers to have previous child-raising experience and confidence, often through previous experience caring for younger siblings or other family members (e.g., cousins, nieces/nephews). The caregiving experience many young mothers possessed was often not acknowledged or valued by adults in the young mothers' social worlds, especially those adults with expert status and administrative authority. Jessica, a 17 year old expectant mother who helped care for a younger sister with a chronic illness as well as a baby brother, explained that her child caregiving experience left her feeling confident about the challenges of young parenting. She disagreed with the assessment of herself as needy regarding child caregiving information.

I always had that responsibility of taking care of [my sister] ever since I was two years old, taking care of her, taking care - and then when my baby brother came out, you know taking care of him. I just loved him! I'd just always change his diaper. I would feed him, I would burp him, I would play with him, I would, you know, wake up and see him. I was so close to my baby brother. I just loved him. He was my baby. And I still do now.[...] still to this day I always take care of my little brother and I always take care of my little sister. I take them out, I feed them, I take them out to go out, I just-you know, I'm not like [their] sister. I'm just like, more like a second or third parent to them. So when I found out I was pregnant, I didn't have the problem inside of me where I was just like, “Oh my god, I don't know how to take care of a kid" or "Oh my God it's gonna be terrible. I don't wanna have a kid right now."

Despite the childcare experience of many of the young mothers, they were perceived to be in need of intensive education and surveillance. This construction of young mothers as inexperienced and lacking proper parenting knowledge had multiple elements: lack of life experience (years lived), assumption of social deprivation due to statistics correlating lower socioeconomic status with early childbearing, and the notion that early childbearing must be unplanned and due to contraceptive ignorance or lack of self-efficacy.

\section{Technological Knowledge}

Although hands-on experience was usually insufficient to qualify young mothers as officially knowledgeable parents, life experience as a "digital native" was adequate to construct them as fluent in information and communications technologies. However, there was an opposing position on this spectrum applied to the most socially and economically marginalized youth in the study. Although all young parents in the study had access to the Internet and smartphones, those with the most transient and marginal lives had the poorest and least reliable access, sometimes losing or having to sell their phones for example, and rarely having a home computer.
Another subset of young mothers in this study had access to technology, but disabilities (sensory, learning, cognitive, or medical) limited their full participation in information technology. Seventeen-year old Courtney, for example, had family members with computer skills and education, but explained that she rarely used computers for schoolwork or social media because she developed migraine headaches whenever she looked at a screen for a prolonged period of time. Given that Courtney came from a middle-class socioeconomic background, neither the polarized discursive construction of the affluent digital native nor that of the marginalized youth without access to technology accurately captured her experience. Such positions that deviated from stereotypes were silenced in two ways, as the minimizing of experiences that did not fit the expected narrative (of digital youth) intersected with the stigma and self-stigma (Ali, Hassiotis, Strydom, \& King, 2012) that impact youth with disabilities, often limiting their desire to speak publicly about their technology access or use challenges.

\section{Social Locations in Information Worlds}

The young parent arena and the construction and valuation of young mothers' expertise therein were shaped in part by social constructions of gender and ethnicity. The social locations of individual young mothers - in other words their positionality at the intersection of identity factors including but not limited to ethnicity, socioeconomic class, and gender-shaped their experiences and relationships with actors in the social worlds within the young parent arena. In particular, gender and ethnic norms were observed to strongly influence the YPPs and related social worlds, informing information interactions and affecting negotiations over the value of different types of knowledge.

\section{Gendered Worlds}

The young parent arena in general, and the YPPs in particular, were highly feminized social worlds. Most information providers, ranging from teachers and youth workers to family and friends, were women. Male staff in these feminized environments assumed the responsibility of role modeling, regularly commenting on gender equity issues and demonstrating "involved fatherhood" or profeminist attitudes-for example teacher Roger describing the way he and his wife balanced night time care of their own baby. Despite the presence of these male role models, the participation of young fathers in programs aimed at young parents was low. This absence reflects the intensive focus on young mothers that was evident in the YPPs, as well as more broadly in society, and may also relate to hegemonic gender norms for young fathers (e.g., pressure to drop out of school to work, or enter vocational training programs). Historically, most young parent services only accepted mothers, but in recent years many have adopted more unisex names and policies. The YPPs in this study were officially open to young fathers, and they occasionally enrolled (usually along with their female partners). 
The YPP staff acknowledged a double bind around father inclusion: while they felt compelled to customize their programs to the participants (primarily young women), they recognized that this might inadvertently make fathers feel unwelcome. When a young father attended a YPP, negotiations often ensued regarding participation in "feminized" activities, for example craft projects or contraceptive education. This focus on young mothers existed in several of the other social information worlds in the arena, ranging from government to the mass media. Official statistics on young fathers were rarely collected, obtaining funding for young father-specific programs was a challenge for community, and there is no "Teen Dad" reality show. The primary discursive construction of young fathers in this study was that of conspicuous silences and absences within the social arena, implying that young fathers are ignorant and unmotivated to learn about parenting due to the intersection of their age and gender.

The interactions and negotiations among social worlds in the young parent arena were also gender-informed. Virtual worlds such as the mass media and Internet notwithstanding, information worlds in the young parent arena varied in degree of direct contact with YPPs, and this degree of contact was often gendered in nature. For example, medicine (masculinized world) was quite separate from the YPP, while public health nursing (feminized world) was intimately intertwined, with nurses frequently visiting and sending information to the YPPs and other programs. Although the physicians that young mothers were seeing on a regular basis-family doctors, obstetrician/gynecologists, and pediatricians-were among the most feminized fields of medicine (Canadian Medical Association, 2015), medicine has historically held, and continues to carry a more masculine connotation than nursing (David, 2000; C. Davies, 1996). The influence of both authoritative health information worlds was strong, but in situations in which a young mother's doctor's advice contradicted public health advice, she was likely to place more authority on the information from her doctordespite, or perhaps because of, this gendered distance.

Paralleling the higher authority placed on the more distant and masculinized information worlds within the young parent arena, higher value was placed by service providers on the more masculinized, technical, or scientific forms of knowledge held by young mothers. Discursive positions that attributed expertise to young mothers in technical matters (e.g., "scientific" mothering practices, fluency with information technology) increased their status within many associated social worlds. Experiential expertise in feminized reproductive and domestic matters, while sometimes valued by peers, did not grant expert status and associated cultural capital. Experience that was too "social" in nature (e.g., about relationships or sexuality) held the potential to stigmatize, either regarding taboo female promiscuity or by being too "non-scientific."

\section{Ethnic and Cultural Norms}

The young parent social arena in Greater Vancouver was reflective of the broader cultural norms of the region. While the young mothers in this study were a diverse group, bringing to the YPPs and other shared spaces a variety of cultural practices, the construction of certain knowledges as valued and authoritative gave preferential treatment to health and parenting practices that conformed to Eurocentric ideals and a culture of "intensive mothering"an ideology of motherhood that requires mothers to seek and use scientific information as well as extensive time and financial resources in monitoring and guiding child development (Hays, 1996). Knowledge and practices that were cast as "ethnic" or "native," generally served to lower young mothers' cultural capital and increase their positions as information needy in various worlds within the young parent arena, including the YPPs and daycare, and with government and health care providers. While professionals who interacted with the young mothers undoubtedly intended to be culturally sensitive - and some worked very hard to value and respect the home cultures of immigrant and refugee students in particular - this was sometimes at odds with the overarching mandate of educational interventions to help young mothers comply with approved Canadian mothering practices (i.e., those promoted by medical associations and public health organizations).

Tensions arose around the assimilation of immigrant mothers and suppression of cultural parenting practices that contradicted hegemonic Canadian norms. Young mothers could respond to such pressures by adhering to their traditional practices or by recognizing the differences in context and (at least publicly) changing their actions/language. In one YPP, during an education session on baby feeding, an immigrant student attempted to disengage from a conversation with staff members who were trying to change her baby-feeding habits by saying, "Us [ethnic group] people; we raise babies kind of differently." The teacher responded by telling her, "This is not culture. This is scientific." The student continued to resist the intervention, stating, "I just follow what my mom told me." Another immigrant young mother from the class was then called upon to model her baby feeding practices, which conformed to current public health recommendations. Through interactions such as this one, young mothers who maintained the cultural parenting practices of their families of origin were constructed as more information needy and less knowledgeable than immigrants who were willing to assimilate.

Indigenous mothers' cultural parenting and health expertise were sometimes seen as non-authoritative in a manner similar to those of immigrant mothers. In addition, many of today's young Indigenous mothers in Canada are in the position of being the first generation in their families after the closure of residential schools and the "sixties scoop" that removed Indigenous children from family in the 196080's (Johnston, 1983; Sinha et al., 2011). JBiebs, whose 
own mother consulted her for parenting advice, was one of the young Native mothers who discussed this positionality. JBiebs' mother and grandmother had not had the opportunity to be fully raised by their own parents due to colonial policies of removal and forced assimilation, and she herself was a ward of the state. However, like other Indigenous interviewees, she articulated a strong desire to parent her own child in a blend of "scientific" and traditional practices, and was recognized within her family and community as a parenting expert. Elements of this dynamic may also be transferrable to other situations in which cohorts of children were not raised by their own parents, effectively robbing them of the ability to pass down parenting knowledge and skills, altering relationships among social worlds in the young parenting arena.

These tensions between marginalized cultural practices and Western, "scientific," intensive mothering was complicated by the fact that not all of the marginalized practices were "traditional" in terms of being pre-colonial. In some cases they were indeed (e.g., infant co-sleeping), but in others (e.g., feeding soft drinks to very young children) they were unhealthy legacies of Western colonization and oppression. Colonization thus manufactured ignorance by suppressing and delegitimizing traditional parenting and health practices. In such cases, while an individual young mother may be naïve to certain parenting information, this was due to the loss or theft of cultural knowledge over generations.

\section{DISCUSSION}

The young parent arena contained multiple social information worlds, comprising both formal spaces for education and surveillance as well as other spaces that functioned as information grounds. Within these worlds, actors including teachers, health professionals, family members, and other youth constructed understandings of expertise and knowledge. Young mothers' experiential expertise was sometimes recognized, but was expected to defer to the knowledge of credentialed experts. Experts such as teachers, youth workers, and health care providers were subject to some of the same tensions as were young parents. Such mid-level experts were often highly aware of competing systems of valuing knowledges, and the many and varied levels and types of expertise young mothers possessed. However, they worked within programs and organizations with a mandate to educate and inform this population in accordance with Western "scientific" and intensive mothering ideologies.

This study focused primarily on Proctor's first and simplest form of ignorance, as a naïve state in which young mothers are discursively constructed to be ignorant in ways that may be remedied by applying information. However, both other forms of ignorance-lost/stolen knowledge and obfuscation of knowledge-were evident as well in young mothers' social information worlds. Chatman's construction of information poverty, however, only partially applied to the positionality and practices of the young mothers in the current study, who did manage their own release of personal information in exchange for health and social services, and at times colluded with their portrayal as ignorant, aware that their expertise would not be welcomed or valued by experts. However, at the same time, most of the study population lived up to their youth-related reputation for digital literacy and connectedness, and were readily able to access information from beyond the bounds of their immediate social worlds via the Internet, decreasing information imbalances between themselves and experts.

\section{Limitations and Strengths}

As is common for a qualitative study, this investigation did not aim for generalizability. We cannot state with certainty how representative this sample was of the larger population of young mothers. In particular, it is likely that our recruitment methods may not have reached mothers on both the most- and least-disadvantaged ends of the spectrum, as they would be the least likely to be engaged with young parent services such as YPPs. That said, the use of multiple forms of data collection to triangulate and enrich findings, along with the longitudinal approach over 15 months' time, allowed both establishment of trust relationships with study participants and the opportunity to confirm emerging interpretations of the data with service providers and with young mothers themselves, increasing the credibility and dependability of these findings, as well as their likely transferability to populations beyond the study sample.

\section{Implications for Research and Practice}

This study furthers to use of situational analysis as a tool for qualitative investigation in information behavior research, including as a lens through which to analyze information worlds. Findings related to gendered and racialized and age-related discourses of risk underscore much of the extant literature, while contributing to an ongoing discussion of the relationship between agnatology (Proctor, 2008), the study of the cultural production of ignorance, and the theory of information poverty (Chatman, 1996), which includes social practices of disinformation and assessment of situational relevance of information that are largely associated with class. Understanding the social information worlds of young mothers, and in particular the conflicts that may arise between cultural knowledges and western scientific discourses of parenting, can aid in tailoring education programming aimed at supporting the well-being of young mothers and their children. It may be helpful for information providers to consider to what extent stereotypes of young people and young parents may be limiting acknowledgement of lived expertise, even while encouraging pursuit of more formal education that may lead to increased cultural capital across social worlds. Culturally-specific parenting and educational interventions (e.g., Indigenous parenting programs) are well-equipped to bridge information worlds that promote both traditional parenting practices and the modern Canadian context, recognizing the value of young parents' experiential expertise while providing valuable new information. 


\section{CONCLUSION}

This analysis explored the information worlds of young mothers, and examined the construction of expertise according to social hierarchies of power therein. It elucidated discourses of knowledge and ignorance applied to young mothers, in which the "teen mom" is portrayed paradoxically as knowledgeable and networked yet ignorant and inexperienced. Despite the fact the many young parents have a great deal of childcare experience, they are (stereo)typically perceived as in need of intensive parenting education by virtue of their age. Social and cultural expertise, while sometimes respected by peers and educators, did not generally increase the cultural capital of young mothers. While many education interventions are built on models that portray information as key to building knowledge and changing behaviours, young mothers may already possess expertise that may conflict with the authoritative information being communicated. Navigating these complexities with nuance, rather than understanding young mothers as unilaterally information needy, may enable more effective interventions to improve the wellbeing of young mothers and their children.

\section{ACKNOWLEDGMENTS}

The authors would like to thank the young parents and service providers who participated in this study, sharing their many forms of knowledge and expertise. This study was funded by the Canadian Institutes of Health Research grants GIR-127079 and MOP-126032.

\section{REFERENCES}

Anwar, E., \& Stanistreet, D. (2015). "It has not ruined my life; it has made my life better": a qualitative investigation of the experiences and future aspirations of young mothers from the North West of England. Journal of Public Health, 37(2), 269-76. https://doi.org/10.1093/pubmed/fdu045

Barcelos, C. A. (2013). Producing (potentially) pregnant teen bodies: biopower and adolescent pregnancy in the USA. Critical Public Health, 24(4), 476-488. https://doi.org/10.1080/09581596.2013.853869

Barcelos, C. A., \& Gubrium, A. C. (2014). Reproducing Stories: Strategic Narratives of Teen Pregnancy and Motherhood. Social Problems, 61(3), 466-481. https://doi.org/10.1525/sp.2014.12241

Basch, C. E. (2011). Teen pregnancy and the achievement gap among urban minority youth. The Journal of School Health, 81(10), 614-618. https://doi.org/10.1111/j.17461561.2011.00635.x

Batool, S. H., \& Webber, S. (2016). Conceptions of school libraries and the role of school librarians: findings from case studies of primary schools in Lahore. In Proceedings of the Ninth International Conference on Conceptions of Library and Information Science, , Uppsala, Sweden, June 27-29, 2016 (Vol. 9). Uppsala, Sweden. Retrieved from 1/colis/colis $1606 . h$ html
Berger, P. L., \& Luckmann, T. (1967). The social construction of reality: a treatise in sociology of knowledge. Garden City, N.Y: Doubleday.

Bonell, C. (2004). Why is teenage pregnancy conceptualized as a social problem? A review of quantitative research from the USA and UK. Culture, Health \& Sexuality, 6(3), 255-272. https://doi.org/10.1080/13691050310001643025

Breheny, M., \& Stephens, C. (2010). Youth or disadvantage? The construction of teenage mothers in medical journals. Culture, Health \& Sexuality, 12(3), 307-322. https://doi.org/10.1080/13691050903513234

Burnett, G., \& Jaeger, P. T. (2008). Small worlds, lifeworlds, and information: The ramifications of the information behaviours of social groups in public policy and the public sphere. Information Research, 13(2). Retrieved from http://informationr.net/ir/132/paper346.html

Camic, C., Gross, N., \& Lamont, M. (2011). Social Knowledge in the Making. University of Chicago Press.

Chabot, C., Shoveller, J. A., Johnson, J. L., \& Prkachin, K. (2010). Morally Problematic: Young Mothers' Lives as Parables about the Dangers of Sex. Sex Education: Sexuality, Society and Learning, 10(2), 201-215.

Charmaz, K. (2007). Constructing grounded theory: a practical guide through qualitative analysis. Thousand Oaks, CA: Sage Publications.

Charmaz, K. (2009). Constructivist grounded theory methods. In J. M. Morse (Ed.), Developing grounded theory: The second generation (pp. 127-154). Walnut Creek, CA: Left Coast Press.

Chatman, E. A. (1991). Life in a small world: Applicability of gratification theory to information-seeking behavior. Journal of the American Society for Information Science, 42(6), 438-449. https://doi.org/10.1002/(SICI)10974571(199107)42:6<438::AID-ASI6>3.0.CO;2-B

Clarke, A. (2005). Situational analysis: grounded theory after the postmodern turn. SAGE.

Clarke, A. E. (2003). Situational Analyses: Grounded Theory Mapping After the Postmodern Turn. Symbolic Interaction, 26(4), 553-576. https://doi.org/10.1525/si.2003.26.4.553

Collins, H., \& Evans, R. (2007). Rethinking Expertise. Chicago, IL: University of Chicago Press.

Collins, H. M., \& Evans, R. (2002). The Third Wave of Science Studies Studies of Expertise and Experience. Social Studies of Science, 32(2), 235-296. https://doi.org/10.1177/0306312702032002003

Dervin, B. (1992). From the mind's eye of the "user": The sense-making qualitative-quantitative methodology. In Qualitative Research in Information Management (pp. 61-84). Libraries Unlimited. Retrieved from http://www.ideals.illinois.edu/bitstream/handle/2142/228 1/Dervin1992a.htm

Dryburgh, H. (2000). Teenage pregnancy. Health Reports, 12(1), 9-19. 
Duncan, S. (2007). What's the problem with teenage parents? And what's the problem with policy? Critical Social Policy, 27(3), 307-334. https://doi.org/10.1177/0261018307078845

Fields, J. (2005). "Children Having Children": Race, Innocence, and Sexuality Education. Social Problems, 52(4), 549-571. https://doi.org/10.1525/sp.2005.52.4.549

Fisher, K. E., \& Naumer, C. M. (2006). Information Grounds: Theoretical Basis and Empirical Findings on Information Flow in Social Settings. In New Directions in Human Information Behavior (pp. 93-111).

Fraser, A. M., Brockert, J. E., \& Ward, R. H. (1995). Association of young maternal age with adverse reproductive outcomes. The New England Journal of Medicine, 332(17), 1113-1117. https://doi.org/10.1056/NEJM199504273321701

Furstenberg, F. F. (1976). The Social Consequences of Teenage Parenthood. Family Planning Perspectives, 8(4), 148-164. https://doi.org/10.2307/2134201

Gold, R., Kawachi, I., Kennedy, B. P., Lynch, J. W., \& Connell, F. A. (2001). Ecological analysis of teen birth rates: association with community income and income inequality. Maternal and Child Health Journal, 5(3), 161-167.

Grace, D., \& Sen, B. (2013). Community resilience and the role of the public library. Library Trends, 61(3), 513541.

Greyson, D. (2016). Evolution of information practices over time. Proceedings of the Association for Information Science and Technology, 53(1). doi: 10.1002/pra2.2016.14505301052

Greyson, D. (2017). Health information practices of young parents. Journal of Documentation, 73(5).

Habermas, J. (1991). The Structural Transformation of the Public Sphere: An Inquiry Into a Category of Bourgeois Society. MIT Press.

Hanna, B. (2001). Negotiating motherhood: the struggles of teenage mothers. Journal of Advanced Nursing, 34(4), 456-464.

Hoffman, S. D., \& Maynard, R. A. (2008). Kids Having Kids: Economic Costs \& Social Consequences of Teen Pregnancy. Washington, DC: The Urban Institute Press.

Jaeger, P. T., \& Burnett, G. (2010). Information Worlds: Social Context, Technology, and Information Behavior in the Age of the Internet. London, UK: Routledge.

Karlova, N. A., \& Fisher, K. E. (2013). "Plz RT": A social diffusion model of misinformation and disinformation for understanding human information behaviour. Information Research, 18(1), paper 573.

Kelly, D. M. (2000). Pregnant with meaning: teen mothers and the politics of inclusive schooling. New York, NY: Peter Lang.

Kelly, D. M. (2007). Young Mothers, Agency and Collective Action: Issues and Challenges. Journal of the Motherhood Initiative for Research and Community Involvement, $\quad 9(1) . \quad$ Retrieved from http://pi.library.yorku.ca/ojs/index.php/jarm/article/view/ 5131

Langille, D. B. (2007). Teenage pregnancy: trends, contributing factors and the physician's role. CMAJ, 176(11), 1601-1602. https://doi.org/10.1503/cmaj.070352

Loudon, K., Buchanan, S., \& Ruthven, I. (2016). The everyday life information seeking behaviours of first-time mothers. Journal of Documentation, 72(1), 24-46. doi: 10.1108/JD-06-2014-0080

McKenzie, P. J. (2003). A model of information practices in accounts of everyday-life information seeking. Journal of Documentation, 59(1), 19-40. https://doi.org/10.1108/00220410310457993

Penman-Aguilar, A., Carter, M., Snead, M. C., \& Kourtis, A. P. (2013). Socioeconomic disadvantage as a social determinant of teen childbearing in the U.S. Public Health Reports (Washington, D.C.: 1974), 128 Suppl 1, $5-22$.

Proctor, R. (2008). Agnotology: A missing term to describe the cultural production of ignorance (and its study). In R. Proctor \& L. L. Schiebinger (Eds.), Agnotology: the making and unmaking of ignorance. Stanford, Calif: Stanford University Press.

Savolainen, R. (1993). The sense-making theory: Reviewing the interests of a user-centered approach to information seeking and use. Information Processing \& Management, 29(1), 13-28. https://doi.org/10.1016/03064573(93)90020-E

Schiebinger, L. (2004). Feminist History of Colonial Science. Hypatia, 19(1), 233-254. https://doi.org/10.1111/j.1527-2001.2004.tb01276.x

Scholl, T. O., Hediger, M. L., Huang, J., Johnson, F. E., Smith, W., \& Ances, I. G. (1992). Young maternal age and parity. Influences on pregnancy outcome. Annals of Epidemiology, 2(5), 565-575.

Seamark, C. J., \& Lings, P. (2004). Positive experiences of teenage motherhood: a qualitative study. The British Journal of General Practice, 54(508), 813-818.

Statistics Canada. (2012). Population and dwelling counts, for census metropolitan areas, 2011 and 2006 censuses (2011 Census). Ottawa, Ontario: Government of Canada. Sullivan, S., \& Tuana, N. (Eds.). (2007). Race and epistemologies of ignorance. Albany: State University of New York Press.

Tuominen, K., \& Savolainen, R. (1997). A social constructionist approach to the study of information use as discursive action. Information Research, ISIC '96 Proceedings of an international conference on Information seeking in context, 81-96.

Yu, L. (2012). Towards a reconceptualization of the "information worlds of individuals." Journal of Librarianship and Information Science, 44(1), 3-18. https://doi.org/10.1177/0961000611424586

Zipf, G. K. (1949). Human behavior and the principle of least effort (Vol. xi). Oxford, UK: Addison-Wesley Press. 